Check for updates

Cite this: RSC Adv., 2018, 8, 33968

Received 29th August 2018

Accepted 24th September 2018

DOI: $10.1039 / \mathrm{c} 8 \mathrm{ra07212d}$

rsc.li/rsc-advances

\section{Transition metal/Brønsted acid cooperative catalysis enabled facile synthesis of 8- hydroxyquinolines through one-pot reactions of ortho-aminophenol, aldehydes and alkynes $\dagger$}

\author{
Shuyan Yu, D* Jingxin Wu, Hongbing Lan, Hanwen Xu, Xiaofei Shi, Xuewen Zhu* \\ and Zhigang Yin*
}

A convenient and straightforward three-component one-pot strategy has been developed for the synthesis of 8-hydroxyquinoline derivatives. Under the cooperative catalysis of silver(I) triflate and trifluoroacetic acid, ortho-aminophenol reacted with a range of aldehydes and alkynes under mild reactions, affording the corresponding 8-hydroxyquinoline derivatives with good to excellent yields. These transformations exhibited exceptional substrate generality and functional group compatibility.

\section{Introduction}

As a privileged scaffold, 8-hydroxyquinoline has been found in many natural products and drug candidates with remarkable biological and pharmaceutical activities. ${ }^{1-9}$ Moreover, 8hydroxyquinolines have been gaining attention in metallocene complex catalyzed transformations, in which they are utilized as effective multidentate ligands. ${ }^{10-21}$ In view of the remarkable importance of this class of heterocyclic compounds, the field of 8-hydroxyquinoline synthesis is continuously gaining attention. Although 8-hydroxyquinolines could be prepared by hydrolysis of 8-haloquinolines ${ }^{22}$ or 8 -aminoquinolines, ${ }^{23}$ the latter two quinolone derivatives were not easily accessible. The classical Skraup's procedure for quinoline derivatives suffered from harsh reaction conditions and poor yields. ${ }^{24-26}$ The Friedlander reaction was limited due to the instability of 2-aminobenzaldehyde, which is mostly in situ generated by reduction of 2-nitrobenzaldehyde derivatives. ${ }^{27,28}$ In the last 20 years, transition-metal or Brønsted-acid catalysis toward quinoline derivatives have been extensively studied. ${ }^{29-36}$ What's confusing is that 8-hydroxyquinolines were rarely involved in these reports. ${ }^{37-40}$ Considering the importance in pharmacology and functional materials chemistry, the development of more facile and economic synthetic approached for 8-hydroxyquinolines is highly desirable.

Initially 8-hydroxyquinoline was envisioned to arise from hydroarylation-cyclization of propargylamine $\mathbf{C}$ followed by oxidation/aromatization, which might to be formed through

Material and Chemical Engineering College, Zhengzhou University of Light Industry, Zhengzhou 450002, Henan, People's Republic of China

$\dagger$ Electronic supplementary information (ESI) available. CCDC 1864450 and 1864452. For ESI and crystallographic data in CIF or other electronic format see DOI: $10.1039 / \mathrm{c} 8 \mathrm{ra} 07212 \mathrm{~d}$ nucleophilic addition of acetylide-[M] B to iminium $\mathbf{A}$. That is, under the cooperative catalysis of transition metal and Brønsted-acid, 8-hydroxyquinoline might be efficiently generated through one-pot reaction of ortho-aminophenol, aldehyde and alkyne (Scheme 1). Suitable catalyst match was considered to be crucial for this transformation.

\section{Results and discussion}

To establish proof of concept, we carried out the reaction of ortho-aminophenol 1, benzaldehyde $2 \mathrm{a}$ and phenylacetylene $\mathbf{3 a}$ as the archetypal. Our study began with the evaluation of different metal catalyst in the presence of one equivalent of TFA (Table 1, entry 1-6). We were pleased to find that the reaction with AgOTf as alkye-philic catalyst could generate the desired 8hydroxyquinoline compound $4 \mathrm{a}$ in $72 \%$ yield with benzylamine 5a as the byproduct ${ }^{41}$ (entry 1). Other Brønsted acid were also examined (entry 7-9). Suitable strength of acidity proved to be crucial for the multicomponent transformation. TFA seemed to be the best. Control experiments indicated the necessity of the both catalysts. Without the participation of TFA, no product could be obtained. And the reaction got obviously suppressed in

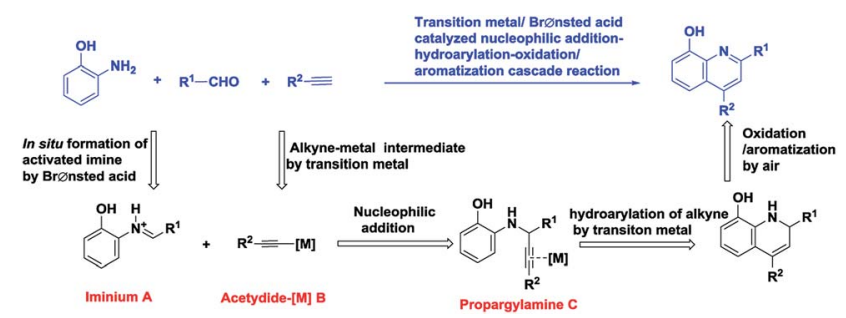

Scheme 1 Possible synthetic pathway for 8-hydroxyquinoline. 
Table 1 Optimization of reaction conditions ${ }^{a}$

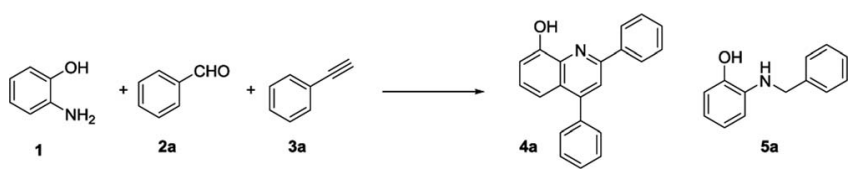

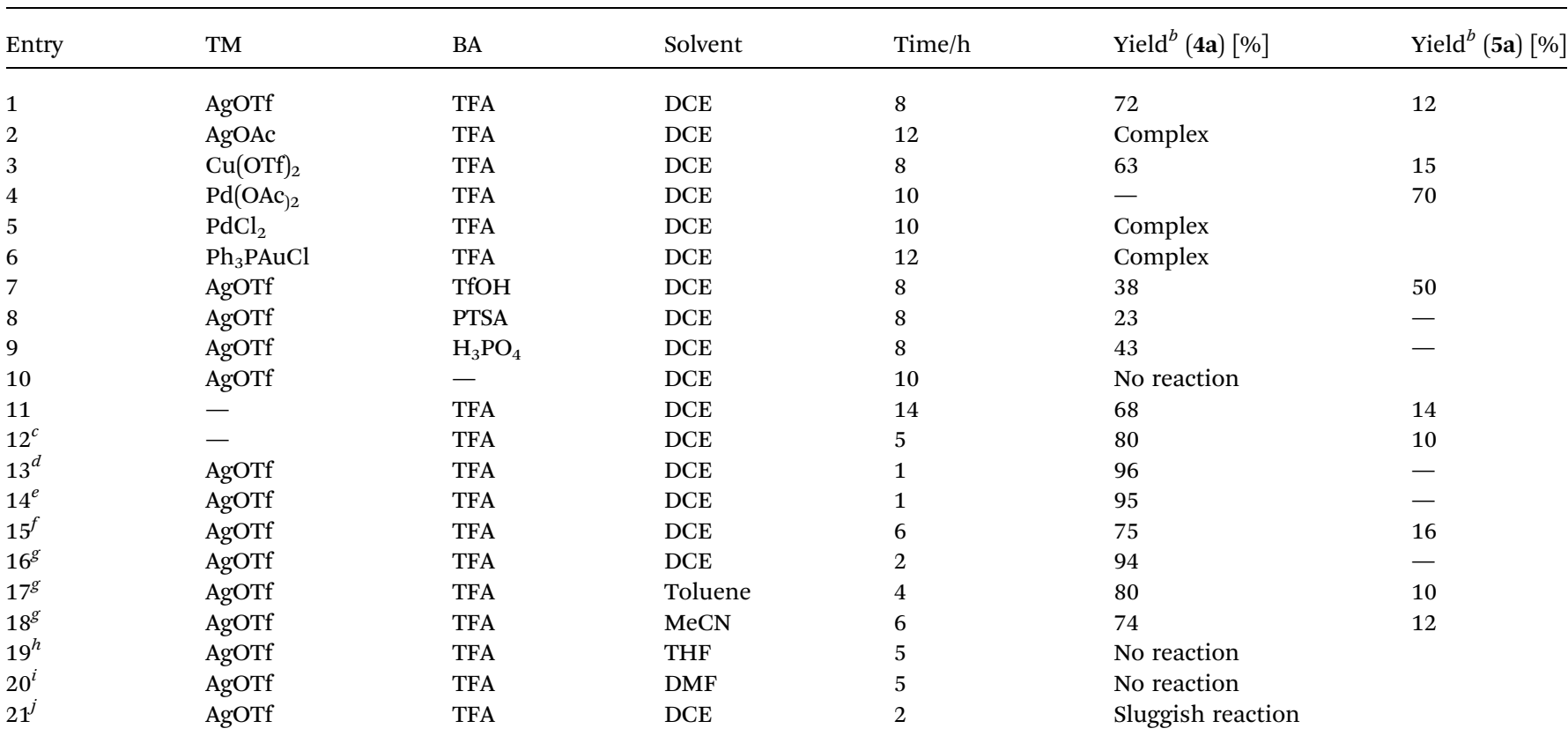

${ }^{a}$ Conditions: 1 (1.1 mmol, 1.1 equiv.), $2 \mathrm{a}$ ( $1 \mathrm{mmol}, 1$ equiv.), 3a (1.2 mmol, 1.2 equiv.), TM (transition metal, 5 mol\%), BA (Brønsted acid, 100 mol\%) in $4.0 \mathrm{~mL}$ solvent under atmosphere at $80{ }^{\circ} \mathrm{C}$ for $8 \mathrm{~h} .{ }^{b}$ Isolated yield based on $2 \mathrm{a}^{c}{ }^{c}$ TFA $(400 \mathrm{~mol} \%) .{ }^{d} \mathrm{AgOTf}(5 \mathrm{~mol} \%)$ and TFA (400 mol\%). ${ }^{e}$ AgOTf $(1 \mathrm{~mol} \%)$ and TFA $(400 \mathrm{~mol} \%) .{ }^{f}$ AgOTf $(1 \mathrm{~mol} \%)$ and TFA $(200 \mathrm{~mol} \%) .{ }^{g}$ AgOTf $(0.5 \mathrm{~mol} \%)$ and TFA $(400 \mathrm{~mol} \%) .{ }^{h}$ AgOTf $(0.5 \mathrm{~mol} \%)$ and TFA $(400 \mathrm{~mol} \%)$ at $60{ }^{\circ} \mathrm{C} .{ }^{i}$ AgOTf $(0.5 \mathrm{~mol} \%)$ and TFA $(400 \mathrm{~mol} \%)$ at $100{ }^{\circ} \mathrm{C} .{ }^{j}$ AgOTf $(0.5 \mathrm{~mol} \%)$ and $\mathrm{TFA}(400 \mathrm{~mol} \%)$ at $60{ }^{\circ} \mathrm{C}$.

the absence of silver (entry 10 and 11). Unexpectedly, when the ratio of TFA increased to $400 \mathrm{~mol} \%$, 8-hydroxyquinoline compound 4 a was collected with higher yield along with greatly reduced reaction time (entry 12 and 13). To our delight, when AgOTf decreased to $0.5 \mathrm{~mol} \%$, a parallel yield was also observed (entry 14-16). Solvent and temperature optimization revealed that other medias are not suitable in terms of yield comparable to that in DCE at $80{ }^{\circ} \mathrm{C}$ (entry 17-21).

With the optimized reaction conditions in hand (Table 1, entry 16), we examined the AgOTf/TFA system for one-pot synthesis of 8-hydroxyquinoline derivatives from ortho-aminophenol 1, various aldehydes 2 and alkynes 3. Table 2 illustrates the wide generality and substrate scope of this tandem reaction. To our delight, satisfactory yields were observed for all substrate examined. For the variation on aromatic aldehyde, different electron-donating or electron-withdrawing substituents at either the para-, meta- or ortho-position on the aryl group were all tolerated to yield $\mathbf{4 a - q}$ in high yields. Aromatic aldehydes with electron-donating group afforded better results than those with electron-withdrawing group (4a-d vs. 4e-f). Notably, strongly electron-deficient $p$-nitrobenzaldehyde gave a complex reaction, without desired product identified. Comparing with electron effect, the steric hindrance exerted less influence on these transformations. It should be noted steric crowded aromatic aldehydes with multiple substituents could work effectively in the one-pot cascade reactions to give 8-hydroxyquinoline derivatives $\mathbf{4 1 - q}$ in acceptable yields. Aliphatic aldehyde and heteroaromatic aldehyde were effective substrates, generating $\mathbf{4 r}$ and $\mathbf{4 s}$ in $93 \%$ and $87 \%$ yield respectively. The reactions proceeded smoothly for aryl alkynes with either electron-withdrawing or electron-donating substituents present on the aromatic ring to afford the desired products in moderate to excellent yields $(\mathbf{4 t}-\mathbf{4 v})$. Electron density provided certain impact on the reactions, and those with electronreleasing group gave a slightly low yield. Alkyl alkyne was also an effective substrate. 8-Hydroxyquinoline derivative $\mathbf{4 w}$ was collected in nearly equivalent yield. The structures of obtained compounds were characterized by NMR spectrum and further confirmed by single-crystal X-ray diffraction analysis of compound $4 \mathrm{c}$ and $4 \mathrm{e}$.

\section{Experimental section}

\section{Materials and methods}

All chemicals were obtained from commercial suppliers and used without further purification. Melting points were measured using a TY-60 microscopic apparatus. ${ }^{1} \mathrm{H}$ NMR and ${ }^{13} \mathrm{C}$ NMR spectra were recorded with Bruker $400 \mathrm{M}$ or $600 \mathrm{M}$ instruments. Chemical shifts were measured relative to tetramethylsilane (0.00 ppm) as internal standard. 
Table 2 Synthesis of 8-hydroxyquinoline derivatives from aminophenol, aldehydes and alkynes ${ }^{a, b}$
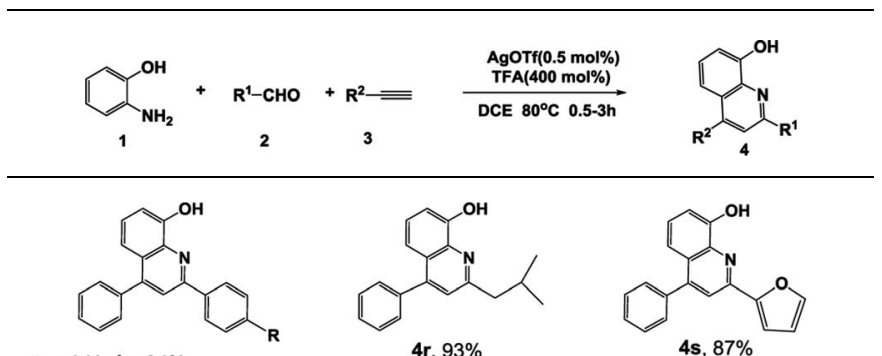

$\mathrm{R}=4-\mathrm{H}, \mathbf{a}, 94 \%$ $4-\mathrm{CH}_{3}, \mathbf{4 b}, 95 \%$ $4-\mathrm{OCH}_{3}, 4 \mathrm{c}, 96 \%$ $4-\mathrm{OH}, 4 \mathrm{~d}, 92 \%$ 4-COOMe, $4 \mathrm{e}, 85 \%$ 4-NO $\mathrm{N}_{2}, 4 \mathrm{f}$, complex $4-\mathrm{Cl}, \mathbf{4 g}, 94 \%$ $4-\mathrm{Br}, 4 \mathrm{~h}, 92 \%$ 4-Br, $4 \mathbf{h}, 92 \%$ $2-\mathrm{Br}, 4 \mathrm{j}, 84 \%$ 2-F, 4k, 90\% 2,6-di-F,4I, 78\% 2,4,6-tri- $\mathrm{CH}_{3}, 4 \mathrm{~m}, 91 \%$ 2,4-di-Cl, 4 n, $86 \%$ 2-Br-5-OMe, 4o, $82 \%$ 2-Br-4,5-di-OMe, $4 p, 85 \%$ 3-OMe-4- $\mathrm{COCH}_{3}, 4 \mathbf{4}, 84 \%$
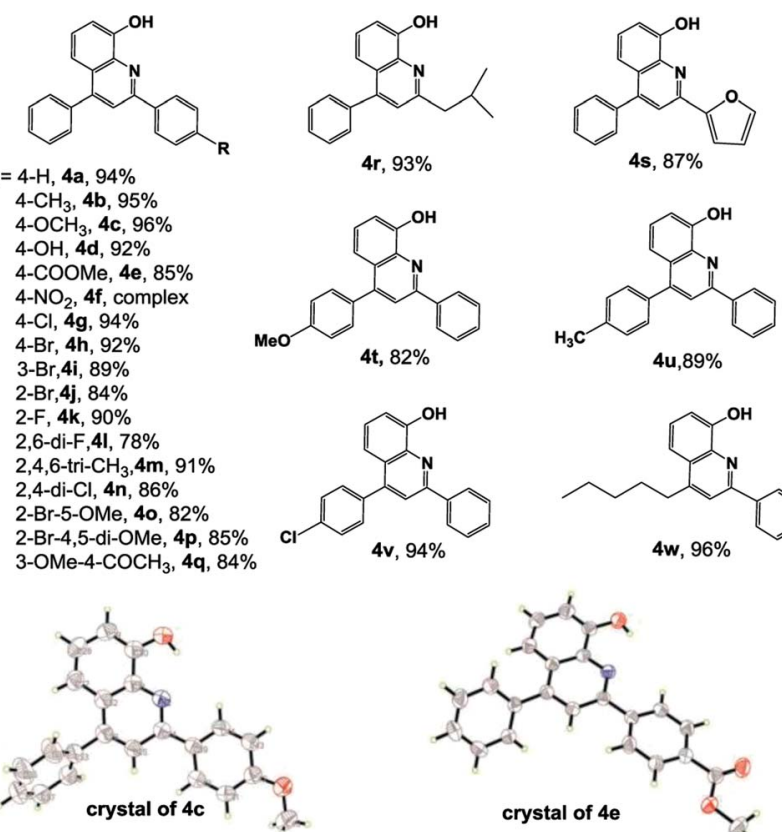

$4 u, 89 \%$
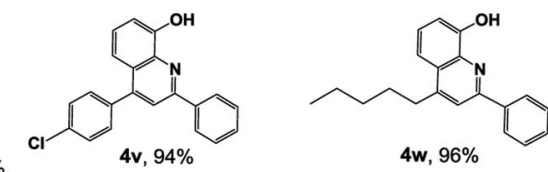

$4 w, 96 \%$

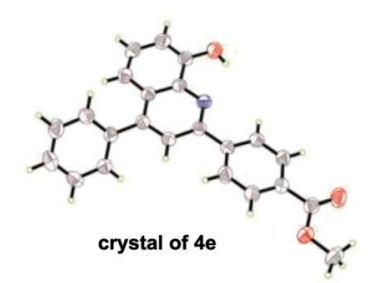

${ }^{a}$ Conditions:1 (1.1 mmol), 2 (1 mmol), 3 (1.2 mmol.), AgOTf (0.5 mol\%), TFA (400 mol\%) in $4.0 \mathrm{~mL}$ DCE under atmosphere at $80{ }^{\circ} \mathrm{C} .{ }^{b}$ Isolated yield based on 2 .

\section{Synthetic procedures for 8-hydroxyquinoline derivatives}

Ortho-aminophenol $(1.1 \mathrm{mmol})$ and aldehyde $(1 \mathrm{mmol})$ were added into a round-bottomed flask with $4 \mathrm{~mL}$ dichloroethane. The vessel was then charged with silver(I) triflate $(0.5 \mathrm{~mol} \%)$ and trifluoroacetic acid (400 mol\%). After stirring for $10 \mathrm{~min}$, alkyne (1.2 mmol) was added dropwise. The resulting mixture was stirred at $80{ }^{\circ} \mathrm{C}$ until aldehyde consumed completely. The reddish-brown solution was cooled to room temperature, diluted with dichloromethane $(10 \mathrm{~mL})$ and water $(10 \mathrm{~mL})$, and then neutralized with $\mathrm{NaHCO}_{3}$ (aq) to pH 7. The aqueous layer was extracted with dichloromethane and the combined organic phase was dried over anhydrous sodium sulfate. After evaporation of solvent, the residue was purified by silica gel chromatography (petroleum ether/ethyl acetate).

\section{Conclusions}

In summary, we have disclosed a highly efficient and practical multicomponent reaction for the construction of 8-hydroxyquinoline scaffold under cooperative AgOTf/TFA catalysis with commercially available materials. A range of valuable 8hydroxyquinoline derivatives are obtained in excellent yields under mild conditions. Various substituents are tolerated on aldehydes and alkynes, thus enabling the vast expansion of substituent architectures on 8-hydroxyquinoline framework.

\section{Conflicts of interest}

There are no conflicts to declare.

\section{Acknowledgements}

We are grateful to the support from the National Natural Science Foundation of China (21602207), the Foundation of Henan Educational Committee (17A150022) and the Doctoral Research Fund of Zhengzhou University of Light Industry (2014BSJJ009).

\section{References}

1 S. Ariyasu, Y. Mizuseda, K. Hanaya and S. Aoki, Chem. Pharm. Bull., 2014, 62, 642-648.

2 W. Li, E. Gerard, O. Masaki, O. M. Bautista-Aguilera, I. Tsutomu, M. Ignacio, I. Isabel, S. Abdelouahid, M. B. H. Youdim and R. Alejandro, Eur. J. Med. Chem., 2014, 80, 543-561.

3 M. Kubanik, H. Holtkamp, T. SC6hnel, S. M. F. Jamieson and C. G. Hartinger, Organometallics, 2015, 34, 5658-5668.

4 Y. N. Song, H. Xu, W. Chen, P. Zhan and X. Liu, MedChemComm, 2015, 6, 61-74.

5 F. Prati, C. Bergamini, R. Fato, O. Soukup, J. Korabecny, V. Andrisano, M. Bartolini and M. L. Bolognesi, ChemMedChem, 2016, 11, 1284-1295.

6 M. Shamsipur, Z. Memari, M. R. Ganjali, P. Norouzi and F. Faridbod, J. Pharm. Biomed. Anal., 2016, 118, 356-362.

7 S. Narwal, S. Kumar and P. K. Verma, Res. Chem. Intermed., 2017, 43, 2765-2798.

8 B. Pippi, P. Reginatto, G. D. Machado, V. Z. Bergamo, D. F. Lana, M. L. Teixeira, L. L. Franco, R. J. Alves, S. F. Andrade and A. M. Fuentefria, Med. Mycol., 2017, 55, 763-773.

9 X. Yang, P. Cai, Q. Liu, J. Wu, Y. Yin, X. Wang and L. Kong, Bioorg. Med. Chem., 2018, 26, 3191-3201.

10 W. M. Wang, H. X. Zhang, S. Y. Wang, H. Y. Shen, H. L. Gao, J. Z. Cui and B. Zhao, Inorg. Chem., 2015, 54, 10610-10622.

11 J. S. Carletto, K. C. Roux, H. F. Maltez, E. Martendal and E. Carasek, J. Hazard. Mater., 2008, 157, 88-93.

12 S. Roy, S. Basu, M. Anitha and D. K. Singh, Korean J. Chem. Eng., 2017, 34, 1740-1747.

13 X. Su, F. Yang, Y. Wu and Y. Wu, Org. Biomol. Chem., 2018, 16, 2753-2756.

14 S. Y. Wang, W. M. Wang, H. X. Zhang, H. Y. Shen, L. Jiang, J. Z. Cui and H. L. Gao, Dalton Trans., 2016, 45, 3362-3371.

15 W. M. Wang, Y. H. Ren, S. Wang, C. F. Zhang, Z. L. Wu, H. Zhang and M. Fang, Inorg. Chim. Acta, 2016, 453, 452-456. 16 F. Núñez-Zarur and R. Vivas-Reyes, J. Mol. Struct.: THEOCHEM, 2008, 850, 127-134.

17 E. V. Nosova, G. N. Lipunova, T. V. Stupina, P. A. Slepukhin, M. S. Valova and V. N. Charushin, Russ. J. Gen. Chem., 2014, 84, 1771-1776. 
18 O. B. Petrova, M. O. Anurova, A. A. Akkuzina, R. R. Saifutyarov, E. V. Ermolaeva, R. I. Avetisov, A. V. Khomyakov, I. V. Taydakov and I. C. Avetissov, Opt. Mater., 2017, 69, 141-147.

19 Y. Wu, T. Guo, D. Shu, W. Zhang, F. Luan, L. Shi and D. Guo, Luminescence, 2018, 33, 855-862.

20 Y. Tang, Y. Huo, H. U. Sheng, K. Zhang, F. Zhao and X. Ouyang, Chem. J. Chinese. U., 2014, 35, 48-53.

21 S. Wu, X. Zhong, H. Zeng, W. You and W. Zhou, J. Lumin., 2018, 195, 120-125.

22 S. Xia, L. Gan, K. Wang, Z. Li and D. Ma, J. Am. Chem. Soc., 2016, 138, 13493-13496.

23 M. Gershon, D. D. Clarke and M. Gershon, Monatsh. Chem., 1996, 127, 331-337.

24 S. E. Denmark and S. Venkatraman, J. Org. Chem., 2006, 71, 1668-1676.

25 H. Saggadi, D. Luart, N. Thiebault, I. Polaert, L. Estel and C. Len, RSC Adv., 2014, 4, 21456-21464.

26 G. A. Ramann and B. J. Cowen, Tetrahedron Lett., 2015, 56, 6436-6439.

27 J. Marcocontelles, E. PeL Rezmayoral, A. Samadi, M. A. D. C. Carreiras and E. Soriano, Chem. Rev., 2009, 109, 2652-2671.

28 M. Fallahmehrjardi, Mini-Rev. Org. Chem., 2017, 14, 187-196.
29 T. Iwai and M. Sawamura, ACS Catal., 2015, 5, 5031-5040.

30 E. Vessally, L. Edjlali, A. Hosseinian, A. Bekhradnia and M. D. Esrafili, $R S C A d v$., 2016, 6, 99781-99793.

$31 \mathrm{X} . \mathrm{Xu}, \mathrm{W}$. Liu, Z. Wang, Y. Feng, Y. Yan and X. Zhang, Tetrahedron Lett., 2016, 57, 226-229.

32 J. B. Bharate, R. A. Vishwakarma and S. B. Bharate, RSC Adv., 2015, 5, 42020-42053.

33 H. Z. S. Huma, R. Halder, S. S. Kalra, J. Das and J. Iqbal, Tetrahedron Lett., 2002, 43, 6485-6488.

34 X. Zhang, B. Liu, X. Shu, Y. Gao, H. Lv and J. Zhu, J. Org. Chem., 2012, 77, 501-510.

35 R. I. Khusnutdinov, A. R. Bayguzina and U. M. Dzhemilev, J. Organomet. Chem., 2014, 768, 75-114.

36 S. Naidoo and V. Jeena, Synthesis, 2017, 49, 2621-2631.

37 N. Sudhapriya, A. Nandakumar and P. T. Perumal, RSC Adv., 2014, 4, 58476-58480.

38 X. Zhang, X. Xu, L. Yu and Q. Zhao, Asian J. Org. Chem., 2014, 3, 281-284.

39 Y. Zhang, P. Li and L. Wang, J. Heterocycl. Chem., 2011, 48, 153-157.

40 G. A. Ramann and B. J. Cowen, Molecules, 2016, 21, 1-23.

41 Side product 5a was envisioned to be formed through reduction of imine by dihydroquinoline intermediate as proposed by Iqbal group's work (ref. 33). 